\title{
3D LASER SCANNING SURVEY FOR CULTURAL HERITAGE. A FLEXIBLE METHODOLOGY TO OPTIMIZE DATA COLLECTION
}

\author{
C. Costantino ${ }^{1}$, D. Prati ${ }^{1, *}$, G. Predari ${ }^{1}$, C. Bartolomei $^{1}$ \\ ${ }^{1}$ Department of Architecture, University of Bologna, Bologna, Italy - (carlo.costantino2, davide.prati5, giorgia.predari, \\ cristiana.bartolomei)@unibo.it
}

Commission II, WG II/8

KEY WORDS: Laser Scanning, Optimization Methodology, 3D Reconstruction, Cultural Heritage, Survey, Data Collection

\begin{abstract}
:
The paper describes an operational working methodology to be applied for surveys with phase-shift laser scanning, which allows defining a guidelines system to optimize in-field data collection. While reducing the number of scan positions still using the same quality, it is possible to obtain smaller files, in order to limit the computational requirements during editing and post-production. Nonetheless, this methodology guarantees results that are qualitatively comparable to the standard data collection process. Consequently, the angle ranges have been analyzed to find a value that guarantees for the survey a point cloud lighter and more manageable and, at the same time, that maintains a reasonable accuracy. Subsequently, two parameters were defined, "redundancy" and "closeness", to find an operational process that allows to schematize what is usually achieved with the help of experience in the field: to evaluate the minimum number of scan points that can ensure the necessary overlap for optimal coverage of the entire building surveyed. After defining the study of the ideal situation, the model is applied in a case study, situated in a densely built context, typical of European historical urban centers: the main façade of the G. Ciamician Institute of Chemistry of the University of Bologna (Italy).
\end{abstract}

\section{INTRODUCTION}

In recent years, the cultural heritage sector, in particular in the architectural area, has been increasingly affected by the development of innovative surveying techniques.

Traditional survey instruments are often insufficient for cultural heritage, which is characterized by irregular and complex shapes due not only to the numerous decorations and moldings but also to the deterioration problems. 3D laser scanning and other innovative survey techniques have a high degree of detail that faithfully reproduces these objects (Fontana et al., 2002).

Consequently, these geomatic technological solutions have allowed surveying the specificities and problems of cultural sites accurately. As a result, these instruments have provided exciting opportunities for the survey and monitoring of the structural health of buildings (Prati et al., 2018; Zinno et al., 2019), infrastructures, and cultural heritage (Artese et al., 2019).

The study and preparation of the scanning points is a fundamental phase when planning a survey campaign. At this moment, the survey goals have already been established. According to the goals, some parameters (requested accuracy, overlapping, resolution) have to be set to evaluate the minimum number of scan points that can ensure full coverage of buildings and a sufficiently detailed point cloud (Vacca et al., 2012). Besides, a reconnaissance work can be helpful to make sure there are no obstacles or other elements that may prevent an exact laser scanning process (Rajendra et al., 2014).

The planning of a survey campaign offers both to reduce the production time of the single scan and to obtain a survey with excellent resolution. The resolution governs the level of identifiable details within the scanned point cloud and can be classified into angular, range, and intensity resolution. The angular resolution is the ability to distinguish two points on adjacent sightlines. The results show that the scanning angle effect can still be moderate until 15 degrees (Ling et al., 2008).
Furthermore, other studies have indicated how the properties of the buildings and the environmental conditions can affect the accuracy of the survey: the influence of surface characteristics, e.g., roughness, reflectivity, color (Bucksch et al., 2007); environmental conditions, e.g., ambient light, humidity, temperature (Pfeifer et al., 2007).

Otherwise, some research has studied the most suitable survey techniques for specific types of buildings: for example, those concerning the medieval towers, the bell towers, and other very high historical architectures. In fact, for this type of constructions, the height makes it difficult to accurately survey them using traditional techniques (Bertacchini et al., 2010).

The ideal set-up for the surface scanning of an object is to position the laser scanner so that the laser beam is nearly perpendicular to the surface. Due to the scanning conditions of the environment, such an ideal set-up is not possible in practice. For this reason, the interaction between incidence angle, redundancy, and point cloud quality has been the subject of several studies (Soudarissanane et al., 2008).

During a survey campaign, the building is usually scanned from several standpoints; for this reason, the considerations related to the accuracy of the scan are strictly connected to the concept of data redundancy. Indeed, the laser scanning detects the position of individual points in space, but when two adjacent scans are joined, it is highly unlikely that they precisely measure the same point. Therefore, within the same surface, there is a redundancy of points, which is higher, the closer the scan points are.

This research aims to illustrate an operational working methodology using objective parameters. Guidelines are thus defined to reduce the scan spots number as much as possible without altering the quality of the data collected.

The first implementation of this methodology was made during the survey of a medieval building block in the historic town center of "San Giovanni in Persiceto" (Bologna, Italy), where

* Corresponding author 
we studied the potentiality and the issues of this methodology in a densely built context, characterized by a very tight street section and comparably high buildings.

As technologies and computing power have rapidly developed, this often makes it unnecessary to worry about the amount of data collected. Either way, the research takes this aspect into account to allow using even not very fast terrestrial laser scanners or already outdated workstations. In this way, it is possible to optimize both the timing necessary for the data collection process and to obtain smaller files in order to limit the computational costs during editing and post-production.

\section{THE CASE STUDY: THE G. CIAMICIAN INSTITUTE}

The main front of the G. Ciamician Institute of Chemistry of the University of Bologna was chosen as the case study to test this working methodology. The building is in the historic city center, inside the University district, between San Giacomo and Belmeloro Streets. The main front extends along Selmi Street for a length of approximately $135 \mathrm{~m}$ (Fig. 1 and Fig. 2). The construction is almost symmetrical in plan, except for the portion at the intersection with Belmeloro Street.

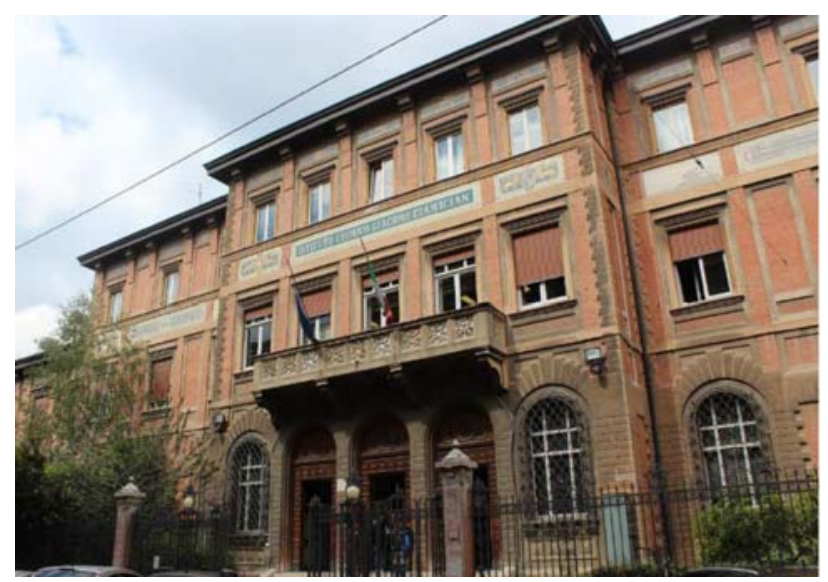

Figure 1. Main façade of the G. Ciamician Institute on Selmi Street, characterized by numerous decorations made with Liberty-style ceramic tile strips

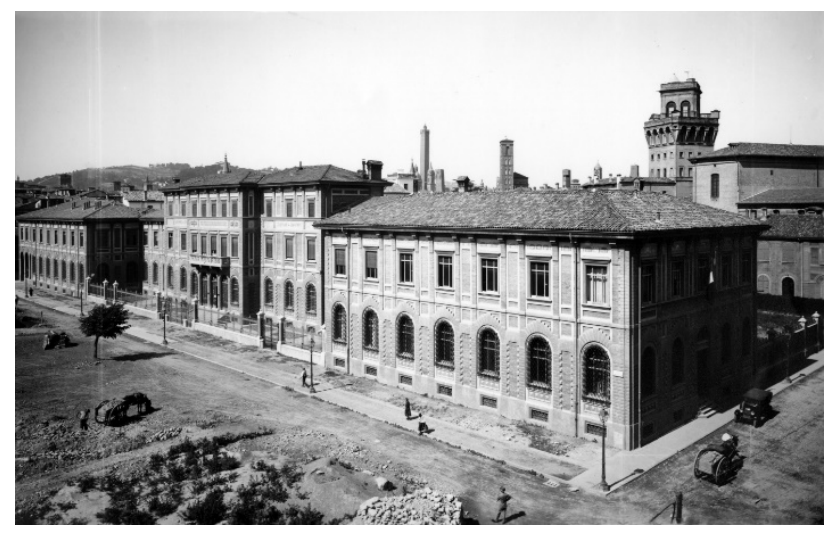

Figure 2. Main façade of the G. Ciamician Institute on Selmi Street - (“Archivio Storico dell’Università di Bologna, sezione Archivio Fotografico")

The prospect on Belmeloro Street is the only one that presents porticos for all its extension, with two spans on the main front. The entire building volume consists of three structurally autonomous buildings, which housed the Institutes of General Chemistry (in the center), Pharmaceutical Chemistry and Agricultural Chemistry, on the left and right sides, respectively. Currently, the building houses numerous chemical laboratories, classrooms, and offices for professors and researchers, which are located mainly in the two lateral arms and on the second floor. The complex is protected by the "Soprintendenza Archeologia, Belle Arti e Paesaggio per la città Metropolitana di Bologna e le province di Modena, Reggio Emilia e Ferrara" ("Superintendence of Archeology, Fine Arts and Landscape for the Metropolitan City of Bologna and the provinces of Modena, Reggio Emilia, and Ferrara”) since 1982.

The design of the building started in 1910 by the engineer Francesco Boriani, a member of the "Ufficio Edilizia e Arte del Comune di Bologna" ("Construction and Art Department of the Municipality of Bologna"). The structural design was made by a proper office of the "Genio Civile" ("Public Works Department") specially created for University buildings, while the architectural and façade design was elaborated by the famous Bolognese architect Edoardo Collamarini (Luminasi, 1931). Likewise, as it was usually done in other University buildings dating back to those years, the exterior fronts are characterized by extraordinary attention to architectural details. Notably, a neo-medieval brick façade was adopted for the Ciamician Institute, in order to link with the Bolognese cultural identity (Gresleri, 1997).

The project was part of the so-called "Seconda Convenzione", an agreement concluded in 1911 between the University of Bologna, the local authorities, and the State. These agreements (called "convenzioni") were operational tools aimed at the development and enhancement of the University through ambitious buildings' projects. The first agreement was concluded in 1897 and was followed by the second one in 1911 and a third one in 1929 (Lama, 1987).

The construction of the building followed a massive demolition of existing structures between Belmeloro and San Giacomo Streets. In October 1916, the construction of the Institute started, and the entire masonry structure was built in two years. Afterward, in 1918, the construction was interrupted due to the First World War, and the realization could resume only in 1924. When Collamarini died in 1928, the works were not yet completed (Tega, 1987).

Indeed, the building was completed and inaugurated only in 1931, thanks to additional funding obtained through the third agreement (Consorzio per gli edifici universitari, 1938). Subsequently, numerous interventions were made to expand or to perform internal changes. In 1942 a new building was erected close to the north side of the Institute. The project, signed by engineer Remo Palazzoli, envisaged the construction of the new building with a basement and two floors above the ground, to be used for new laboratories. The new building had an architectural language which was adapted to the existing one, with the same moldings and pitched roof. On the contrary, the structure was made with a reinforced concrete frame and external infill made of solid bricks like was usually done in those years. Moreover, this part of the building was elevated in 1987 with a steel structure.

The historic building follows a strongly rational and symmetrical approach, with Selmi Street as the main route. The entrance hall was organized along the median axis, which initially gave access to the large bolognese staircase, divided into two ramps that led to the upper floor. The double-height atrium brings to the lecture hall at the center, while the secondary branches develop to its left and right sides, originally intended for teaching. Collamarini himself designed the vast library and the access staircase. In this space, he placed four columns that local tradition says they were recovered from the ancient "Palazzo Lambertini" demolished in 1910, which had been designed in 1548 . 
The building complex has a vertical load-bearing structure mainly realized in brick masonry, organized on the two main construction directions. In some areas, there are internal reinforced concrete frames made up of pillars and beams that lay on the load-bearing walls and standalone steel pillars. Loadbearing masonry columns support the entrance hall instead. The building has different floor types. On the underground and the ground levels, the floors are generally realized with barrel and cross vaults, but reinforced concrete slabs cover few rooms. In the mezzanine, there are hollow bricks floors, while in the remaining rooms, the floor slabs are reinforced concrete. Finally, the roofs are entirely made of wood.

In particular, the main front on Selmi Street (Fig. 3) has an extension of $135 \mathrm{~m}$ and a variable height between $12.5 \mathrm{~m}$ and 17 $\mathrm{m}$. It is characterized by the extraordinary attention of the architectural elements: the ashlar decoration and other moldings have a limited thickness compared to the brick finish in order to reduce the plastic; numerous decorations are made with strips in Liberty-style ceramic tiles, such as those above the windows on the top floor. In this position, the tiles represent the four elements of Greek chemistry (water, air, earth, and fire), the basis of the existence, according to Greek philosophers like Empedocles. Instead, in the central part of the building, the tile decorations represent the emblems of Alma Mater, the University of Bologna, and the Savoy royal house.
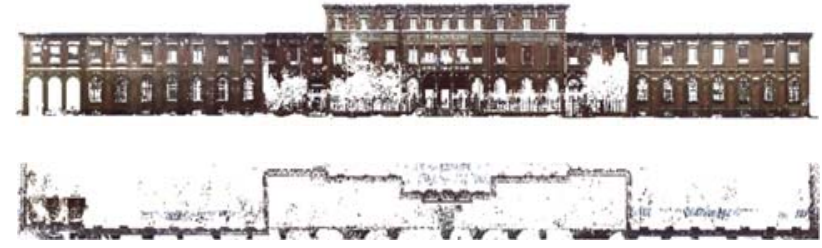

Figure 3. Front and plan of G. Ciamician Institute of Chemistry made by laser scanner survey. In the plan, not defined zones are present because these were inaccessible during the survey, while the presence of trees and gates causes the voids on the front - graphic elaboration by Davide Prati

\section{THE AVAILABLE EQUIPMENT}

A "Faro Cam2 Focus 3D 150" laser scanner was used to survey the Institute (Fig. 4). The tool is a phase shift TLS with excellent portability ( 5 hours of autonomy and $5 \mathrm{~kg}$ of weight) and contained size $(24 \mathrm{~cm} \times 20 \mathrm{~cm} \times 10 \mathrm{~cm})$, equipped with WLAN (Wi-Fi).

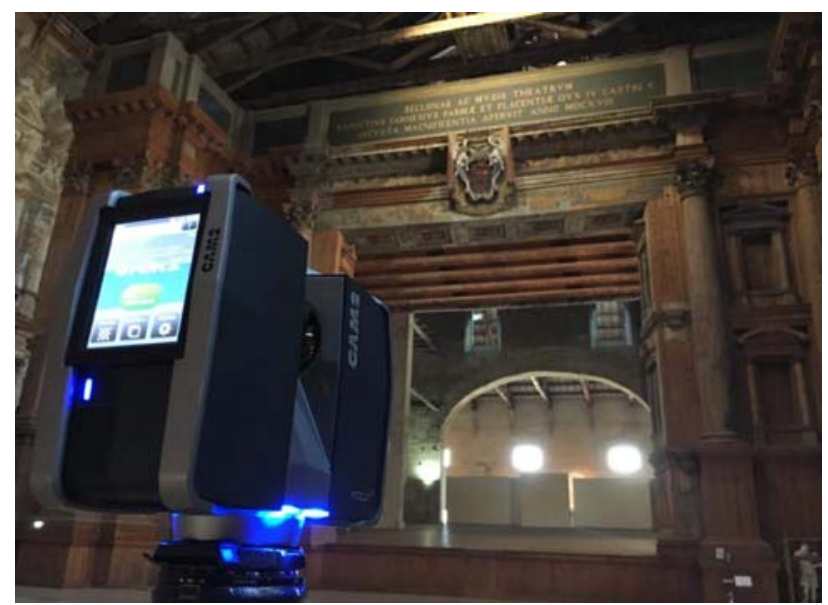

Figure 4. "Faro Cam2, Focus 3D, 150" laser scanning during a survey
The instrument allows measurements with horizontal and vertical resolution of $0.009^{\circ}$, relatively fast with a maximum speed of 976,000 points $/ \mathrm{sec}$, with a distance range from $0.6 \mathrm{~m}$ to $120 \mathrm{~m}$ and a linear distance error of $\pm 2 \mathrm{~mm}$ for a measure among object and scanner in a range between $10 \mathrm{~m}$ and $25 \mathrm{~m}$ with a reflectivity of $90 \%$. Furthermore, the presence of the integrated $70 \mathrm{Mpx}$ camera guarantees the possibility of automatically obtaining the faithful coloring of the point cloud.

"Faro Scene", the software provided by the manufacturer, was used to process the point clouds. This software allows the management of all data processing phases alignment and indexing of the clouds, display of the point cloud model and related photographic archives measuring tool, and finally, the export of orthophotos. The main characteristics provided by the manufacturer are shown in the following table (Tab. 1):

\begin{tabular}{|c|c|}
\hline Type & Phase shift laser scanning \\
\hline Model & Faro Cam2 Focus 3D 150 \\
\hline Production year & 2011 \\
\hline Unambiguity interval & $153,49 \mathrm{~m}$ \\
\hline Range focus 120 & $\begin{array}{l}0,6 \mathrm{~m}-120 \mathrm{~m} \text { indoor or } \\
\text { outdoor with low ambient } \\
\text { light and normal incidence to } \\
\text { a } 90 \% \text { reflective surface }\end{array}$ \\
\hline Range focus 20 & $\begin{array}{c}0,6 \mathrm{~m}-20 \mathrm{~m} \text { at normal } \\
\text { incidence on }>10 \% \text { reflective } \\
\text { surface }\end{array}$ \\
\hline Measurement speed (Pts/Sec) & $\begin{array}{c}122,000 / 244,000 / 488,000 / \\
976,000\end{array}$ \\
\hline Ranging error & $\begin{array}{l} \pm 2 \mathrm{~mm} \text { at } 10 \mathrm{~m} \text { and } 25 \mathrm{~m} \text {, each } \\
\text { at } 90 \% \text { and } 10 \% \text { reflectivity }\end{array}$ \\
\hline Ranging noise & $\begin{array}{l}0,6 \mathrm{~mm}-10 \mathrm{~m} 90 \% \text { refl. } \\
2,2 \mathrm{~mm}-25 \mathrm{~m} 10 \% \text { refl. }\end{array}$ \\
\hline Resolution color unit & Up to 70 Mpixel color \\
\hline Field of view & $300^{\circ} / 360^{\circ}$ \\
\hline Step size (vertical-horizontal) & $\begin{array}{c}0,009^{\circ}(40,9603 \mathrm{D}-\mathrm{Pixel} \text { on } \\
\left.360^{\circ}\right) \\
\end{array}$ \\
\hline Software & SCENE \\
\hline
\end{tabular}

Table 1. Performance specifications of "Faro Cam2 Focus 3D $150 . "$

\section{THE METHODOLOGY}

\subsection{The Data Collection (Standard Conditions)}

A regular geometry characterizes the front of the Institute of Chemistry on Selmi Street. Indeed, this can be identified as a single façade of $135 \mathrm{~m}$, which can be divided into two areas having different height, $12.5 \mathrm{~m}$, and $17 \mathrm{~m}$. Despite these characteristics, the morphology and surrounding context make it a somewhat difficult to survey. Primarily, these difficulties stem from the presence of some overhangs, cars, trees as well as the presence of some inaccessible areas. Therefore, twenty-two scan points were necessary to detect the entire façade (Fig. 5). The first and the last scans are used as connections, to ensure that the instrument might adequately align the Selmi Street façade scans with those on the other fronts. The duration of each scan varies from 3 to 5 minutes with a resolution of $7.6 \mathrm{~mm} / 10 \mathrm{~m}$ and a quality parameter (number of times a point is calculated) equal to $\mathrm{x}$. This survey was characterized by extreme angles of 
inclination between the laser lens and the highest point of the façade.

Generally, they were included in a range between $45^{\circ}$ and $65^{\circ}$. Inevitably this has led to a high redundancy of the points; adding the high number of scansion points, it led to a much heavier final file than necessary. Consequently, the overall point cloud coming from the façade survey is a huge file over $10 \mathrm{~GB}$, consisting of about 94 million points with a variable decimation threshold, with a minimum value of $1 \mathrm{~mm}$ (Fig. 6).
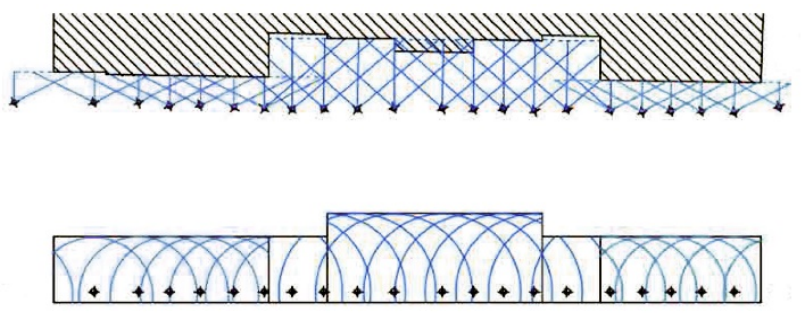

Figure 5. Plan and front view of the project scans in standard conditions - graphic elaboration by Maria Chiara Pugliese

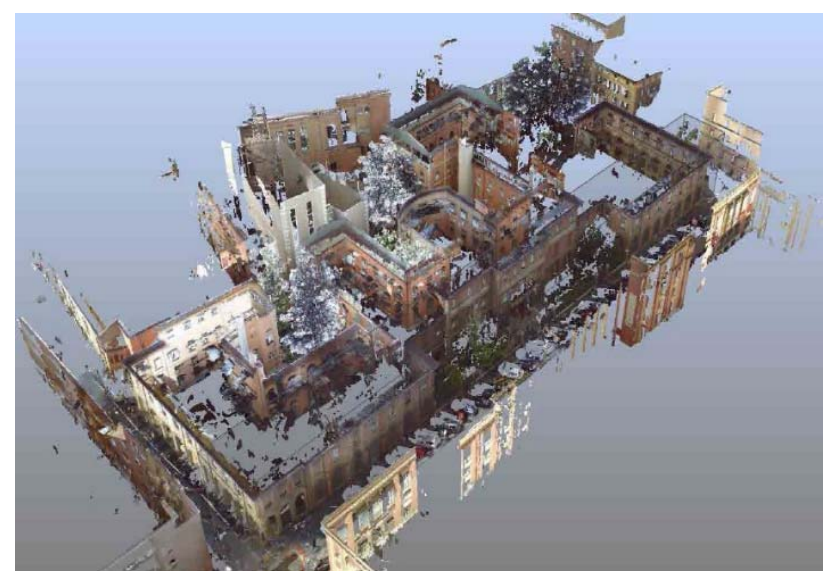

Figure 6. Visualization of the point cloud using "Faro Scene" graphic elaboration by Davide Prati

The overlap of the corner cones is high, always higher than $25 \%$, with average values of around $46.5 \%$, while the average error of the points is $3.14 \mathrm{~mm}$ (Tab. 2).

\begin{tabular}{|c|c|}
\hline Characteristics & Data \\
\hline Point Number & $94 \mathrm{mln}$ \\
\hline File size & $10 \mathrm{~GB}$ \\
\hline Average Overlaps & $46,5 \%$ \\
\hline $\begin{array}{c}\text { Average Points } \\
\text { Error }\end{array}$ & $3,14 \mathrm{~mm}$ \\
\hline $\begin{array}{c}\text { Scan Positions } \\
\text { (number) }\end{array}$ & 22 \\
\hline Scanning time & $3-5 \mathrm{~min}$ \\
\hline
\end{tabular}

Table 2. Data Report from the survey in standard condition

\subsection{Initial Assumptions}

The initial assumption at the basis of the methodology is that the survey benefits from greater accuracy. The lower the inclination produced between the instrument lens and the highest point of the object to be surveyed is, the better the acquired point cloud is. This consideration is well known. Consequently, considering a purely ideal situation, the optimal survey condition is when the instrument rays are perfectly perpendicular to the object to be surveyed (Soudarissanane et al., 2008). Indeed, in this ideal condition, the instrument works optimally, and the overhangs or the high close points with very narrow angles do not generate issues to the survey.

Therefore, the study analyzed the angular ranges able of producing a survey characterized by a lighter and more manageable point cloud and, at the same time, a suitable metric accuracy, and a satisfactory completeness even of the most distant parts. From these analyzes, an "ideal" angle range was defined, between 0 and 30 degrees; however, the range between 30 and 45 degrees also constitutes a reasonable compromise (Fig. 7).

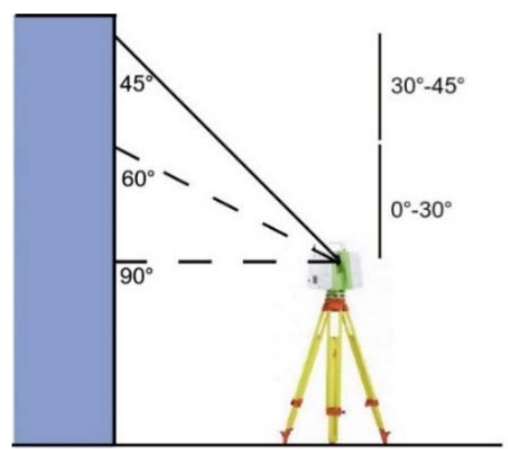

Figure 7. Optimal ranges of laser beam inclination between the object and the scanner. In particular, the ideal range is between

0 and 30 degrees - graphic elaboration by Maria Chiara Pugliese

Subsequently, the density of the point cloud obtained from these ideal conditions was analyzed, considering that, for the case study in standard conditions, the resolution of the survey was $7.6 \mathrm{~mm} / 10 \mathrm{~m}$. This data refers to the distance in $\mathrm{mm}$ between one cloud point and another, within a radius of 10 meters from the instrument focal point. Moreover, after fixing the height of the scanner lens at 2 meters, with simple proportions, it is possible to determinate the density range obtained from the survey, with all the radii between $0^{\circ}$ and $30^{\circ}$ (Fig. 8).

For the façade part with height of $12,5 \mathrm{~m}$ :

$$
\begin{aligned}
& 10: 7,6=18,19: x \rightarrow x=13 \mathrm{~mm} \\
& 10: 7,6=21: x \rightarrow x=15,9 \mathrm{~mm}
\end{aligned}
$$

For the façade part with height of 17,0 m:

$$
\begin{aligned}
& 10: 7,6=25,98: x \rightarrow \quad x=19,7 \mathrm{~mm} \\
& 10: 7,6=30: x \rightarrow x=22,8 \mathrm{~mm}
\end{aligned}
$$

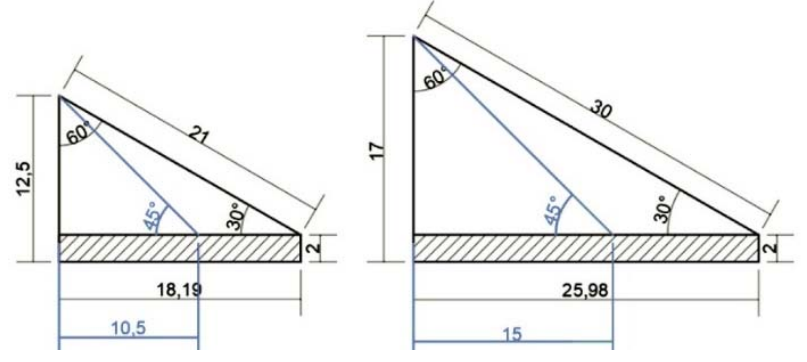

Figure 8. Laser scanner positioning to obtain the ideal condition with a $30^{\circ}$ inclined beam on the two different heights in elevation, $12,5 \mathrm{~m}$, and $17 \mathrm{~m}$ - graphic elaboration by Maria Chiara Pugliese 
Thus, in ideal conditions, the point cloud has a resolution varying between 13 and $15.96 \mathrm{~mm} / 10 \mathrm{~m}$ for the part of the façade with a height of $12.5 \mathrm{~m}$ and between 19.7 and $22 \mathrm{~mm} / 10 \mathrm{~m}$ for the part with the height of $17.0 \mathrm{~m}$. The detected density using this system is believed to be sufficiently precise to the correct survey of the building. Further, the point cloud thus obtained is lighter and more manageable for post-production operations.

\subsection{The Data Collection (Ideal Condition)}

In the ideal survey condition, the whole elevation is always scanned at a maximum angle of 30 degrees. This assumption means to place the laser at about $18 \mathrm{~m}$ when surveying the 12.5 $\mathrm{m}$ high façade part and at about $26 \mathrm{~m}$ for the $17.0 \mathrm{~m}$ high façade, as previously deduced. Usually, this means considering the difficulty of operating in ideal conditions when the model is applied in a real case. In these cases, it is necessary to introduce a customized condition defined by the surrounding context; this "Customized Condition" is going to be subsequently illustrated. The following parameters are introduced to analyze the benefits of operating in these ideal conditions:

The "Closeness": measures the mutual distance between the scan positions.

The "Redundancy":

$$
r=\frac{O}{D}
$$

where $\quad r=$ redundancy

$\mathrm{O}=$ Overlap of the corner cones

$\mathrm{D}=$ Distance between the scan points

By setting the redundancy value equal to zero, a limit condition has been found, where the project scans never intersect with each other. Consequently, this situation cannot be used because it is challenging to combine the collected data in the postproduction phase (Fig. 9).

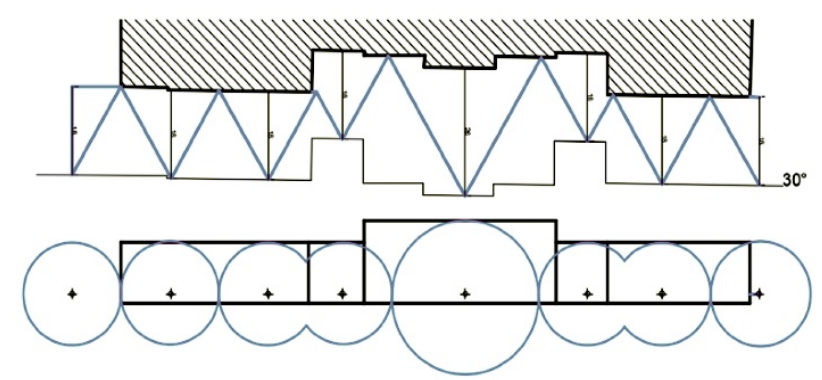

Figure 9. Plan and front view of the project scan spots with zero redundancy - graphic elaboration by Maria Chiara Pugliese

For this reason, it was analyzed the values of the range of redundancy that guarantee a relatively small number of scan points and the optimal coverage of the entire building to be surveyed.

The optimal redundancy range that guarantees these achievements has been determined as follows:

$$
r \leq 1
$$

Therefore, an ideal closeness value is obtained when there is an overall overlap of about $20 \%$ between one scanning point corner cone and the other. This value does not refer to the overlap of the corner cone area but to the linear projection in plan on the base of the cone (Fig. 10).

Considering that in the ideal condition the corner cones are all placed at the same distance and have the same geometry, the closeness value has been calculated at $20 \%$ in the two schemes, respectively referring to the façade part with the height of $12.5 \mathrm{~m}$ and the other of $17 \mathrm{~m}$ :

$$
\begin{aligned}
& C: 21=20: 100 \rightarrow C=4,2 m \\
& C: 30=20: 100 \rightarrow C=6,0 m
\end{aligned}
$$

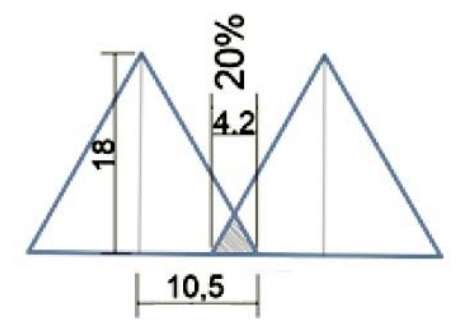

Figure 10. Visualization of the scheme used to identify the Closeness parameter of the scan points - graphic elaboration by Maria Chiara Pugliese

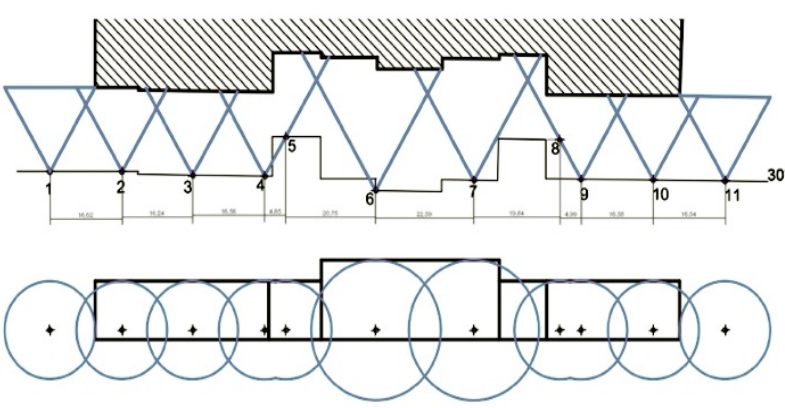

Figure 11. Plan and front view of the project scans with closeness value between 4,2 $\mathrm{m}$ and 6,0 $\mathrm{m}$ - graphic elaboration by Maria Chiara Pugliese

Nevertheless, in situations with a substantial recess in the line of the façade (for example, as occurs in the central part of the Institute of Chemistry), additional scan points must be acquired to ensure that the angle is precisely $30^{\circ}$.

The product of this process (Fig. 11) guarantees a more uniform coverage of the elevation despite a small percentage of overlap. Setting an appropriate closeness allows obtaining a point cloud much lighter and more manageable and, at the same time, sufficiently detailed and homogeneous.

\subsection{Comparison of the result between the ideal survey and standard survey}

By comparing the data of the survey performed in standard conditions with the one performed with the proposed methodology (Fig. 12), it can be seen how the redundancy parameter assumes very different values between the two configurations.

In ideal conditions, this parameter varies between 0.27 and 0.30 in 9 of the 11 total scans, while assuming values of 0.90 and 0.93 in the connection scans between the façade part with different height. In the standard configuration, this parameter assumes values much higher than 2 in 18 of 22 total scans, assuming a maximum value of 4.62 and remaining below the ideal value of 1 only for a single scan $(\mathrm{r}=0.53)$. 
This parameter implicitly indicates that in standard conditions, an excessive scan number has been performed. Consequently, this has a direct impact on the amount of information to be processed after the data collection phase. Besides, the quality of the data is also different in the two configurations: in ideal conditions, all 11 scans were performed while maintaining an inclination of the radius between 0 and 30 degrees; in the standard configuration, only a small portion of the elevation was scanned in this ideal range, while about $50 \%$ of the elevation was surveyed at angles higher than 45 degrees. Therefore, the mutual distance (measured in $\mathrm{mm}$ ) between the points of the clouds produced by the scans in ideal conditions is between 13 and 22.8. In standard conditions, this value varies between 4.45 and 9.14. Thus, the points of the cloud in ideal conditions become sparser, but they are more accurately detected.
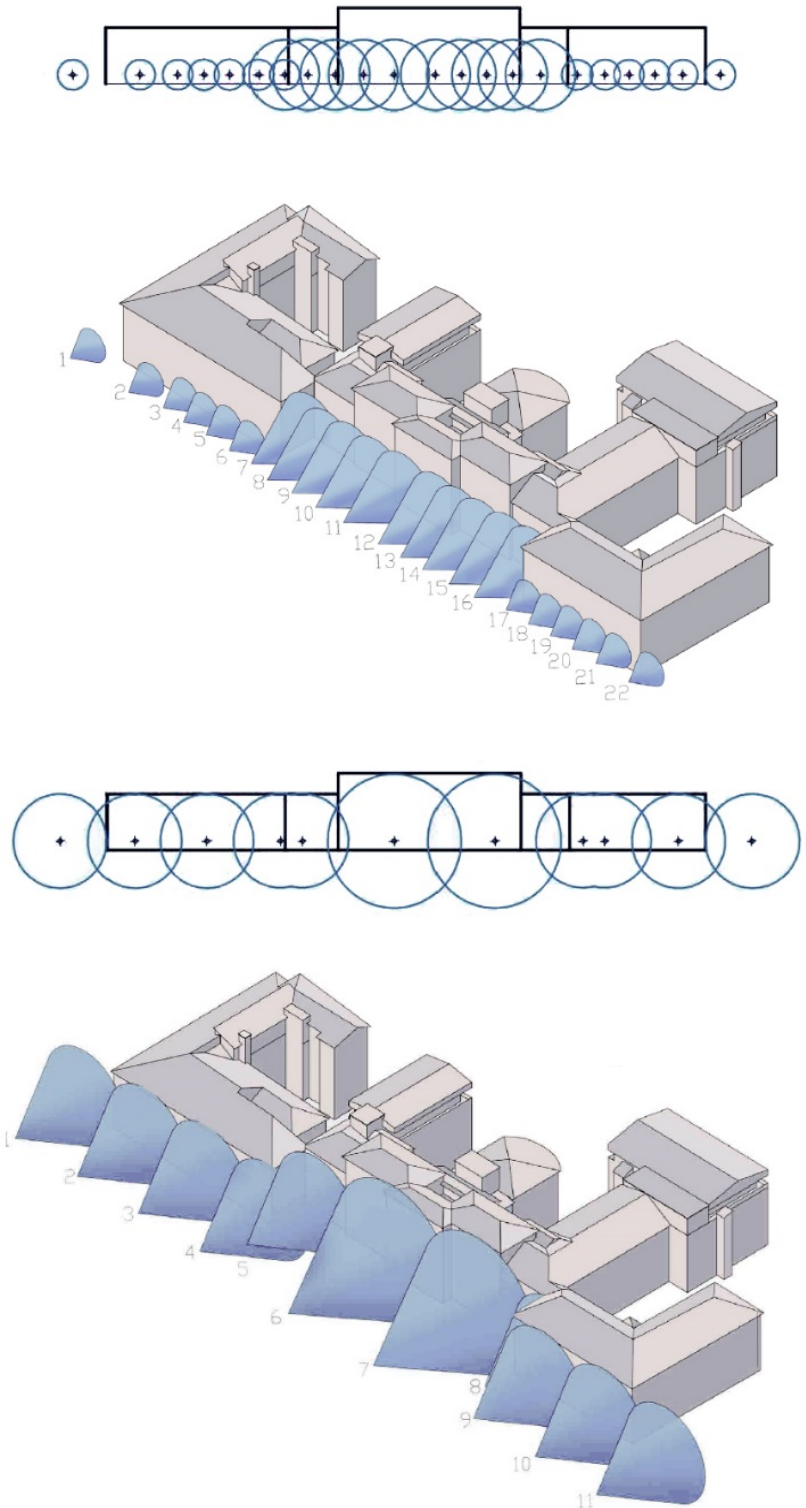

Figure 12. Upper, representation of the laser scanner and threedimensional laser beam projections of the cones taken during the standard survey campaign. Lower, representation of the laser scanner and three-dimensional laser beam projections of the cones contained within a maximum inclination of $30^{\circ}$ obtained from the ideal survey - graphic elaboration by Maria Chiara Pugliese
To conclude, these considerations highlight that when there was not an accurate scanning spots design in standard conditions, the retrieved scans were too close to the façade; this did not optimized neither the timing of the collection phase nor those of the postproduction (Tab. 3).

\begin{tabular}{|c|c|c|}
\hline & Standard Survey & Ideal Survey \\
\hline $\begin{array}{c}\text { Overall Time } \\
(\mathrm{min})\end{array}$ & 66 & 33 \\
\hline $\begin{array}{c}\text { Average } \\
\text { Redundancy }\end{array}$ & 2,96 & 0,40 \\
\hline $\begin{array}{c}\text { Point Distance } \\
(\mathrm{mm})\end{array}$ & $4,45-9,14$ & $13-22,8$ \\
\hline $\begin{array}{c}\text { Point cloud } \\
\text { Weight }\end{array}$ & Heavy & Light \\
\hline
\end{tabular}

Table 3. Comparison between standard survey and the ideal survey

\subsection{The methodology applied to the case study (Customized Conditions)}

The conducted analysis has linked the performed survey with an ideal condition, where the laser beam never hits the surface of the object with an inclination of more than $30^{\circ}$. However, in dense built-up contexts, such as the European historical centers, it is challenging to operate with the scan spots distant enough to maintain the maximum inclination of 30 degrees, as during the case study of the Institute of Chemistry (Fig. 13).

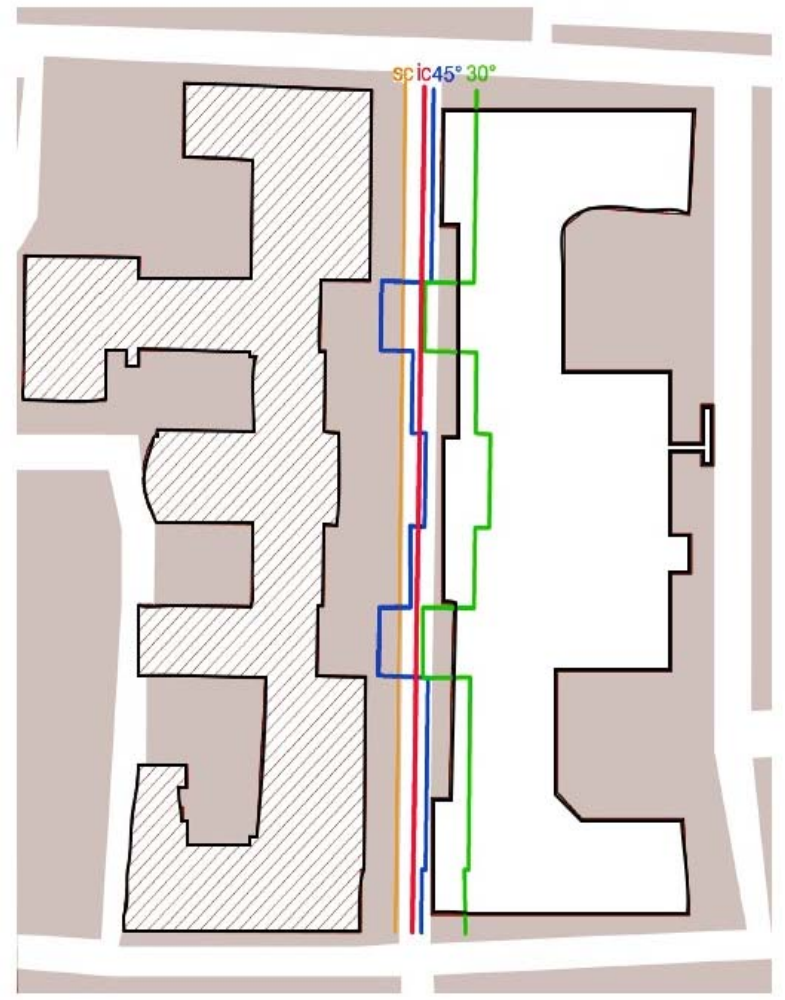

Figure 13. The rails used to conduct the survey: in red, the Customized Condition (IC) between the ideal situation (green rail) and the scanning carried out (orange rail). Behind it, the one with a maximum beam angle of up to $45^{\circ}$ (blue rail) graphic elaboration by Maria Chiara Pugliese 
The survey of the façade on Selmi Street does not allow to acquire scans at the ideal distances of $18 \mathrm{~m}$ and $26 \mathrm{~m}$. For this reason, the "Customized Condition" has been identified for the application of the studied optimization within the building context's limits and specificities allowed. Therefore, a rail was placed at 10.50 meters distance from the foreparts and 18 meters for the remaining portions of the façade.

This configuration lays with a good approximation in the range defined by an inclination of about $45^{\circ}$. For simplicity, this inclination has been maintained as a reference for delineating the cones in plan and elevation. In this case, a closeness value of 4.2 $\mathrm{m}$ and $4.98 \mathrm{~m}$ was also used, corresponding to a $20 \%$ overlap between one a scan spot and the next one.

By analyzing the data deriving from the customized condition (Fig 14.), all the scans guaranteed an almost constant redundancy value, variable between 0.15 and 0.16 . This parameter indicates how the number of scans is further reduced from 11 to 7 . Consequently, the weight of the point cloud is lighter than both the standard and ideal conditions. Nevertheless, the quality of the collected data is still good, although lower than the one in the ideal condition, where the inclination of the beam remains between 0 and 30 degrees.

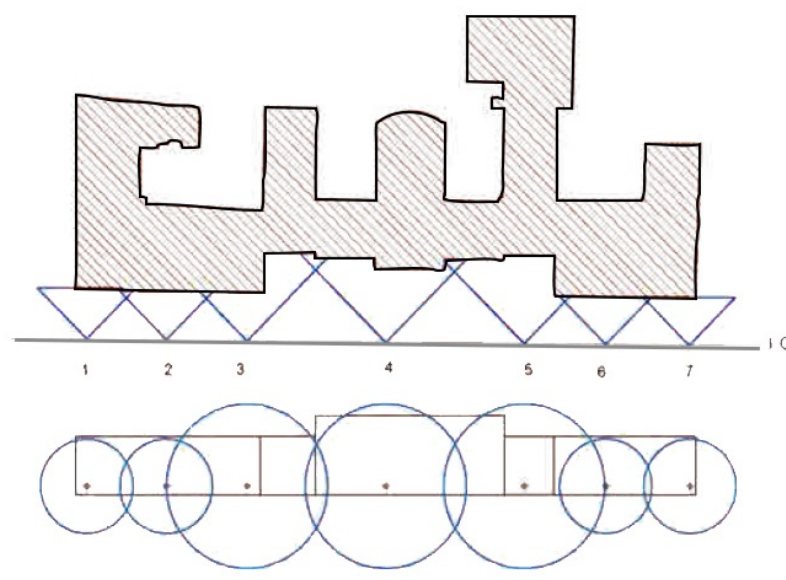

Figure 14. Representation of the laser scanner projections in Customized Condition - graphic elaboration by Maria Chiara Pugliese

\section{CONCLUSIONS}

The paper has illustrated an operational procedure to be conducted before the survey campaign, to simplify the data collection and to obtain an accurate and complete but lighter and more manageable point cloud. By using simple procedures, the parameters of redundancy and closeness have been introduced to establish the position and the minimum number of scan points before carrying out the survey campaign. Therefore, simple guidelines were introduced to reproduce the decisions generally dictated by the user survey experience, during the project of the scan points. Consequently, a survey performed with this methodology ensures a sufficiently detailed and homogeneous point cloud. Indeed, the limited inclination of the laser beam that hits the façade guarantees a limited margin of error and the total cover of the entire elevation.

While considering the use of slightly outdated tools, this data collection methodology guarantees an optimization from different points of view: (i) the weight of the point cloud detected according to this ideal condition is considerably less, having halved the number of scan positions. Consequently, the collected data, during editing and post-production, is considerably undemanding to use by mid-range computers; (ii) similarly, the overall duration of the scanning during the survey is approximately halved, with a consequent saving of time; (iii) the mutual distance between the points (measured in $\mathrm{mm}$ ) of the clouds produced by the new scan positions has increased. Therefore, the cloud points have become sparser, but their quality is not affected or even improved since the produced inclination between the surveyed façade, and the laser scanner beam has significantly decreased.

Furthermore, the use of the ideal inclination range guarantees an improved coverage of all those areas where the overhangs make it impossible to survey the elements that are hidden behind it, contributing to the creation of gaps in the point cloud (as occurs in balconies or other pronounced projections). However, this type of optimization, applied to the specific case study, does not allow to solve some typical problems of the surveys made with this type of instrumentation, such as the presence of vegetation, which does not allow the scanning of hidden points.

In conclusion, the exposed analysis traces some guidelines applicable to real contexts. Therefore, starting from a preventive study of scansion points location, the methodology allows the optimization of the survey of the buildings, even in consolidated contexts such as ancient historical centers. This flexible methodology, even if followed only as a tentative guideline, guarantees a qualitatively good result but with considerable time savings in all work phases.

\section{ACKNOWLEDGMENTS}

Authors are grateful to Maria Chiara Pugliese for her work of data collection and post-production with laser scanning on Ciamician Institute during her Master thesis and to Francesca Maffei for the historical data of Ciamician Institute, collected during her Master thesis.

\section{REFERENCES}

Artese, S., Lerma, J.L., Aznar Molla, J., Sánchez, R.M., Zinno, R., 2019. Integration Of Surveying Techniques To Detect The Ideal Shape Of A Dome: The Case Of The Escuelas Pías Church In Valencia. Int. Arch. Photogramm. Remote Sens. Spatial Inf. Sci. XLII-2/W9, 39-43. https://doi.org/10.5194/isprs-archivesXLII-2-W9-39-2019

Bertacchini, E., Boni, E., Capra, A., Castagnetti, C., Dubbini, M., 2010. Terrestrial Laser Scanner for Surveying and Monitoring Middle Age Towers, in: TS 4D - TLS Application I 4445. Presented at the FIG Congress 2010 Facing the Challenges Building the Capacity, Sydney (Australia), p. 13.

Bucksch, A., Lindenbergh, R.C., Van Ree, J., 2007. Error Budget Of Terrestrial Laserscanning: Influence Of The Intensity Remission On The Scan Quality. https://doi.org/10.13140/RG.2.1.1353.3525

Consorzio per gli edifici universitari, 1938. Opere edilizie eseguite dall'inizio dell'era fascista. Stabilimento tipografico Il Resto del Carlino, Bologna.

Fontana, R., Greco, M., Materazzi, M., Pampaloni, E., Pezzati, L., Rocchini, C., Scopigno, R., 2002. Three-dimensional modelling of statues: the Minerva of Arezzo. Journal of Cultural Heritage 3, 325-331. https://doi.org/10.1016/S12962074(02)01242-6

Gresleri, G., 1997. Edoardo Collamarini e il Ciamician: modernità e continuità, in: Atti Del Simposio Su l'eredità Di 
Giacomo Ciamician a Bologna: Bologna, 25 Ottobre 1996. Lo Sarabeo, Bologna.

Lama, L. (Ed.), 1987. Comune, provincia, università: le convenzioni a Bologna fra enti locali e Ateneo, 1877-1970. Comune : Istituto per la storia di Bologna, Bologna.

Ling, Z., Yuqing, M., Ruoming, S., 2008. Study on the Resolution of Laser Scanning Point Cloud, in: IGARSS 2008 2008 IEEE International Geoscience and Remote Sensing Symposium. IEEE, Boston, MA, USA, pp. II-1136-II-1139. https://doi.org/10.1109/IGARSS.2008.4779200

Luminasi, I., 1931. Assetto generale edilizio della Regia Università degli Studi di Bologna. Il Comune di Bologna Aprile, 3-12.

Pfeifer, N., Dorninger, P., Haring, A.P., 2007. Investigating Terrestrial Laser Scanning Intensity Data: Quality And Functional Relations. Presented at the Proceedings International Conference on Optical 3-D Measurement Techniques VIII, Zurich $(\mathrm{CH})$.

Prati, D., Rrapaj, I., Mochi, G., 2018. Contribution of parametric modeling in the interpretation of deformations and displacements of wooden trusses. SCIRES-IT 8, 105-120. https://doi.org/10.2423/i22394303v8n1p105

Rajendra, Y.D., Mehrotra, S.C., Kale, K.V., Manza, R.R., Dhumal, R.K., Nagne, A.D., Vibhute, A.D., 2014. Evaluation of Partially Overlapping 3D Point Cloud's Registration by using ICP variant and CloudCompare. Int. Arch. Photogramm. Remote Sens. Spatial Inf. Sci. XL-8, 891-897. https://doi.org/10.5194/isprsarchives-XL-8-891-2014

Soudarissanane, S., Lindenbergh, R., Gorte, B., 2008. Reducing The Error In Terrestrial Laser Scanning By Optimizing The Measurement Set-Up, in: Commission I-VIII. Presented at the XXI ISPRS Congress, Beijing, China, p. 6.

Tega, W. (Ed.), 1987. Lo Studio e la città: Bologna 1888-1988. Nuova Alfa, Bologna.

Vacca, G., Deidda, M., Dessi, A., Marras, M., 2012. LASER SCANNER SURVEY TO CULTURAL HERITAGE CONSERVATION AND RESTORATION. Int. Arch. Photogramm. Remote Sens. Spatial Inf. Sci. XXXIX-B5, 589594. https://doi.org/10.5194/isprsarchives-XXXIX-B5-589-2012

Zinno, R., Artese, S., Clausi, G., Magarò, F., Meduri, S., Miceli, A., Venneri, A., 2019. Structural Health Monitoring (SHM), in: Cicirelli, F., Guerrieri, A., Mastroianni, C., Spezzano, G., Vinci, A. (Eds.), The Internet of Things for Smart Urban Ecosystems, Internet of Things. Springer International Publishing, Cham, pp. 225-249. https://doi.org/10.1007/978-3-319-96550-5_10 